\title{
IMMUNOHISTOCHEMICAL STUDY OF Ki-67 ANTIGEN EXPRESSION IN DIAGNOSIS OF PSORIASIS
}

KEY WORDS: Psoriasis, psoriasiform dermatitis, Ki-67, keratinocytes
Depika Sanasam

Sunita Haobam*

Postgraduate Student, Department of Pathology, Jawaharlal Nehru Institute of Medical Sciences (JNIMS), Porompat, Imphal, Manipur, India.

Associate Professor, Department of Pathology, Jawaharlal Nehru Institute of Medical Sciences(JNIMS), Porompat, Imphal, Manipur, India. *Corresponding Author

\section{Urmila Thiyam}

Associate Professor, Department of Pathology, Jawaharlal Nehru Institute of Medical Sciences(JNIMS), Porompat, Imphal, Manipur, India.

L Sushila Devi Professor and Head, Department of Pathology, Jawaharlal Nehru Institute of Medical Sciences (JNIMS), Porompat,Imphal,Manipur, India.

\begin{abstract}
Background: Psoriasis is a common, chronic inflammatory skin disease characterized by scaly white papules and pinpoint bleeding on scratching. Presence of keratinocyte hyperproliferation and abnormal differentiation in the epidermis are some significant features. Histopathologically, it is difficult for the dermatopathologists to differentiate psoriasis from psoriasiform dermatitis when there is a lack of typical features. Aims: To study the Ki-67 antigen expression in the different layers of epidermis of psoriatic skin lesion and its utility in the diagnosis and to differentiate psoriasis from other psoriasiform dermatitis by studying the distribution pattern of Ki-67 immunostaining. Methods: In this cross-sectional study, a total of 91 skin lesions which were clinically labelled as psoriasis and psoriasiform dermatitis were studied, which was confirmed by histopathological examination and followed by Ki-67 immunostaining. The distribution of Ki-67 immunostaining in the supra-basal layer, basal layer and whole epidermis was studied. Results: Ki67 staining was significantly higher in the suprabasal layer and whole epidermis in psoriatic lesions compared to psoriasiform dermatitis. The suprabasal Ki-67 mitotic index was also significantly higher in psoriasis group than psoriasiform dermatitis $(\mathrm{p}<0.05)$. We found that in psoriasis $>50 \% \mathrm{Ki}-67$ positive keratinocytes are scattered in the suprabasal layer of the epidermis in comparison to the psoriasiform dermatitis which is $<50 \%$. Conclusion: We suggest that Ki-67 labelling index can be used for diagnosing psoriasis and also can differentiate it from other psoriasiform dermatitis.
\end{abstract}

\section{Introduction}

Psoriasis is a common, chronic inflammatory disease of the skin often characterized by hyperproliferation and abnormal differentiation of keratinocytes. It is prevalent in $2-3 \%$ population of the world, typically presenting as a dry, scaly papule and plaque which is pink to red in color which upon scratching leads to pin-point bleeding known as Auspitz's sign due to suprapapillary thinning and dilatation of tortuous blood vessel. ${ }^{1}$ Histopathologically, it is seen as elongation of rete ridges and hyperplasia of the epidermis, falling among the various types of psoriasiform reactions besides lichen simplex chronicus and pityriasis rubra pilaris. ${ }^{2}$ This is quite confusing when it comes to the diagnosis except in typical cases. The pathognomonic features of psoriasis can be described as elongation of rete ridges with thickening, Munro's microabcesses (infiltration of neutrophils in the parakeratotic stratum corneum) and Kogoj's pustules (presence of neutrophils in the stratum spinosum) forming sponge-like network of degenerated keratinocytes. However, it is not found in every case of psoriasis and hence limiting in the field of diagnosis.

Although there are many theories regarding the pathogenesis of psoriasis, investigators have opined of the involvement of hyperproliferation of epidermis with abnormal differentiation and increase in turnover rate of epidermis. It is mainly due to the altered $\mathrm{T}$ cell function, which releases cytokines on genetically predisposed individuals. Apoptosis is also found to be one key factor in the proliferation of keratinocytes. Mitotic figures are present in the supra-basal layer of the epidermis in psoriasis pointing towards its diagnosis. ${ }^{3}$ Psoriatic cell show decrease in transit time from basal cell layer to the upper squamous cell layer i.e., 7 days in active psoriasis which differentiates it from the normal cells with 53 days.

Ki-67 is a widely used cell proliferation marker. Ki-67 gene is |www.worldwidejournals.com | present on chromosome 10 and was discovered and named after the city of Kiel, Germany. It is a non-histone nuclear protein present normally in the nucleus of the cell during interphase and also found at the chromosome surface during mitosis. ${ }^{4} \mathrm{Ki}-67$ is expressed in all the phases of the cell cycle i.e., $\mathbf{G}_{1}, \mathbf{S}, \mathbf{G}_{2}$ and mitosis except in $\mathbf{G}_{0}$ phase ${ }^{5,6}$ and therefore, it is useful in the detection of epidermal hyperproliferation. Compared to normal skin or other non psoriatic lesion, Ki-67 index is higher in psoriatic skin lesion. ${ }^{7,8,9}$ In immunohistochemistry, Ki-67 antigen expression analysis is one of the most widely considered indices of cell proliferation. ${ }^{10}$ In this study, we investigated the distribution of psoriasis diagnosed in a tertiary hospital in the North eastern state of India and studied the immunohistochemical utility of Ki-67 antigen expression in diagnosis of psoriasis.

\section{Materials and methods}

Patients: In this cross-sectional study, a total of 91 skin biopsy specimens labelled as psoriasis (76) and psoriasiform dermatitis (15) (out of the total 44815 patients who visited the out-patient Department of Dermatology and Venerology, JNIMS, Imphal) were received in the Histopathological Section of the Department of Pathology, JNIMS, Imphal for a period of two years. These specimens were processed and also confirmed by histopathology. Particulars of the patients along with detailed information such as site, presenting complaints and duration of disease were accounted.

Immunohistochemical analysis: All the specimens were fixed with $10 \%$ formalin and processed in a tissue-processing unit. The formalin fixed paraffin embedded tissues were cut into sections, 3-5 micronmeter in thickness and the tissue sections placed on a slide warmer. It was de-paraffinized and rehydrated with xylene and graded alcohol respectively. The endogenous peroxide was blocked by using $0.3 \%$ hydrogen peroxide for 20 minutes. For antigen retrieval, the sections were cooked in a pressure cooker after treating with TRIS 
buffer and washed with PBS (phosphate buffer solution). The slides were treated with monoclonal antibody (primary antibody) and polymer HRP (horseradish peroxide) labeled secondary antibody and washed with PBS after each step. 3'3 'diaminobenzidine hydrochloride (DAB) was used as the chromogen for immunohistochemistry (IHC). All the IHC slides were counterstained with alcohol free hematoxylin and washed with running tap water. Positive control for immunohistochemistry procedure were used from previously positive specimens of breast carcinoma. Ki-67 positive cells were counted for suprabasal, basal and whole epidermis per $\mathrm{mm}^{2}$ under a light microscope.

Statistical analysis: SPSS (IBM) Version 23 was used to determine the descriptive statistics like Mean, Median, Standard Deviation \& Percentage. Statistical analysis such as Chi square test and Independent sample T test (if $p<0.05$, then it was considered significant) were performed. Confidence interval (CI) of $95 \%$ was taken.

\section{Results}

We studied 76 cases $(84 \%)$ of psoriasis and $15(16 \%)$ cases of psoriasiform dermatitis. The prevalence of psoriasis was $0.2 \%$. The age group of psoriasis patients ranged from $6-80$ years with a mean age of 43.87 ( \pm 17.06 ) years while it was 10 72 years with a mean age of 37.73 ( \pm 21.62 ) years in psoriasiform dermatitis. Highest incidence was seen in the older age group (51-60 years) amongst the psoriasis cases. Out of 76 cases of psoriasis, $52.6 \%$ were females while male was $47.4 \%$. The male: female ratio was $1: 1.1$. Amongst the psoriasiform dermatitis $66.7 \%$ were females while $33.3 \%$ were males. In both the cases, female preponderance was observed. Female preponderance was observed in psoriasis cases in younger age groups $(0-10$ years: $100 \% ; 11-20$ years: $55.6 \%$ ), middle age group ( $41-50$ years: $53.33 \%$ ) as well as in the older age group ( $>60$ years: $60 \%$ ).

Amongst the psoriasis cases, majority were from Meitei community with $65.7 \%$ (50) followed by Muslim community, $18.4 \%$ (14). Naga tribe constituted the least, $1.3 \%$ (1). The most common site of involvement was foot $(22,29 \%)$ followed by leg $(18,24 \%)$ and back $(15,20 \%)$. The least common sites were abdomen, thigh, knee and chest ( $1,1 \%$ each). Majority of these patients complained of pruritis and scaling of the involved skin $57(75 \%)$ followed by thickened skin $10(13 \%)$, pain $5(7 \%)$ and redness $4(5 \%)$.

Histopathologically, psoriatic lesions showed hyperkeratosis, parakeratosis, Munro's micro abscesses, mild spongiosis, spongiform pustules of Kogoj in the epidermis along with capillary dilation and oedema in the papillary dermis with a lymphocytic infiltrate surrounding the capillaries, a few cases of pustular psoriasis displayed marked neutrophilic infiltration throughout the epidermis whereas the psoriasiform dermatitis cases showed hyperkeratosis, marked acanthosis and elongation of rete pegs [Figure 1]

Ki-67 staining were represented by brown coloration of nuclei of the keratinocytes in the epidermis which was counted per $\mathrm{mm}^{2}$ in the basal layer, suprabasal layer and total epidermis in both psoriasis and psoriasiform dermatitis [Figure 2].

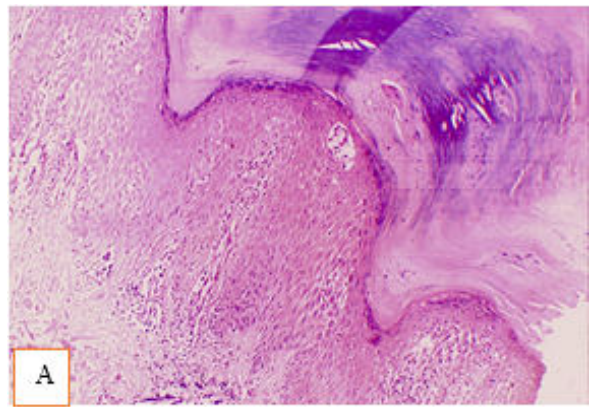

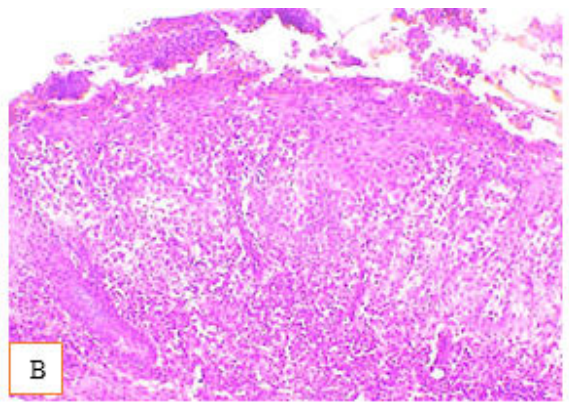

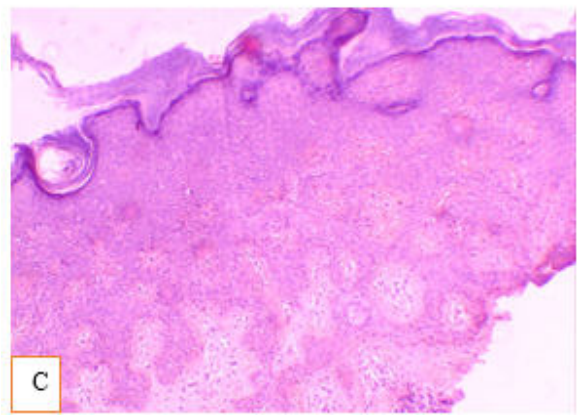

Figure 1: HPE of a case of (A), psoriasis showing hyperkeratosis, Munro's microabscess and spongiotic pustules; (B), pustular psoriasis showing marked neutrophilic infiltration throughout the epidermis; (C), psoriasiform dermatitis showing hyperkeratosis, marked acanthosis and elongation of rete pegs. H\&E 10X.

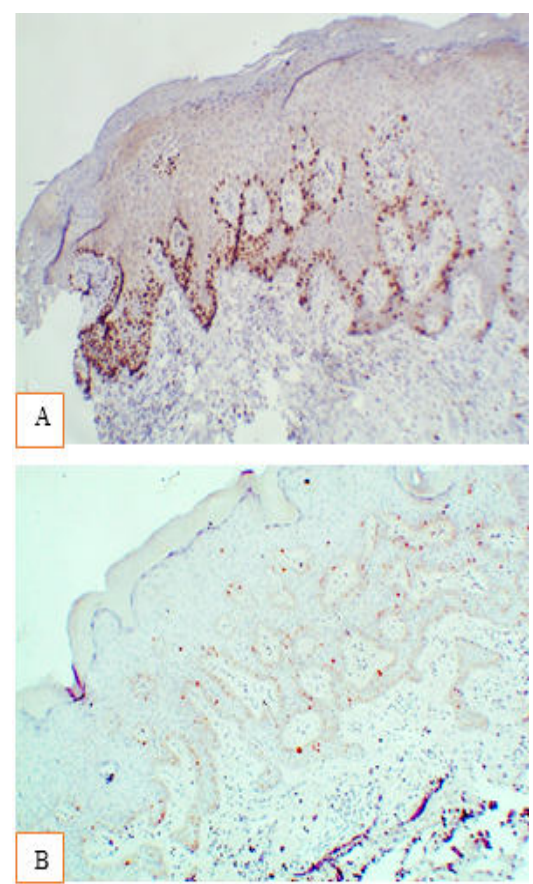

Figure 2: Ki-67 staining of a case of $(A)$ psoriasis showing positivity in basal and suprabasal layer of the epidermis \& (B) psoriasiform dermatitis show positivity predominantly in basal layer of the epidermis. 10X.

The mean total epidermal Ki-67 positive cell count was higher in psoriasis (mean $\pm \mathrm{SD}: 276.24 \pm 94.60 \mathrm{cells} / \mathrm{mm}^{2}$ ) compared to psoriasiform dermatitis (mean \pm SD: $41.33 \pm 21.15$ cells/ $\left.\mathrm{mm}^{2}\right)$ which was also significant $(\mathrm{p}<0.05)$. The mean suprabasal Ki-67 positive cell counts were also found to be significantly higher in cases of psoriasis (196.37 \pm 67.02 cells/ $\mathrm{mm}^{2}$ ) in comparison to psoriasiform dermatitis (mean $\pm \mathrm{SD}$ : $\left.16.07 \pm 7.97 \mathrm{cells} / \mathrm{mm}^{2}\right)(\mathrm{p}<0.05)$ [Table 1$]$. 
Table 1: Comparison of Ki-67 staining between cases of psoriasis and psoriasiform dermatitis.

\begin{tabular}{|c|c|c|c|}
\hline Variable & $\begin{array}{c}\text { Psoriasis(n=76) } \\
\text { Mean ( } \pm \text { SD) }\end{array}$ & $\begin{array}{c}\text { Psoriasiform } \\
\text { dermatitis(n=1 } \\
\text { 5) } \text { Mean ( } \pm \text { SD) }\end{array}$ & P-value \\
\hline \multicolumn{4}{|c|}{ Ki-67 positive cells/mm } \\
\hline Basal layer & $79.743( \pm 2.55)$ & $25.271( \pm 3.36)$ & $<0.05$ \\
\hline $\begin{array}{c}\text { Basal/total } \\
\text { epidermis } \\
\text { ratio(\%) }\end{array}$ & $28.31( \pm 4.96)$ & $60.53( \pm 3.37)$ & $<0.05$ \\
\hline $\begin{array}{c}\text { Suprabasal } \\
\text { layer }\end{array}$ & $196.37( \pm 67.02)$ & $16.07( \pm 7.97)$ & $<0.05$ \\
\hline $\begin{array}{c}\text { Suprabasal/t } \\
\text { otal } \\
\text { epidermis } \\
\text { ratio(\%) }\end{array}$ & $71.65( \pm 4.99)$ & $39.47( \pm 3.37)$ & $<0.05$ \\
\hline $\begin{array}{c}\text { Total } \\
\text { epidermis }\end{array}$ & $276.24( \pm 94.60)$ & $41.33( \pm 21.15)$ & $<0.05$ \\
\hline
\end{tabular}

The suprabasal Ki-67 positivity index (suprabasal /total epidermal cell count ratio) was also found significantly higher in psoriasis group (mean \pm SD: $71.65 \pm 4.99 \%$ ) than psoriasiform dermatitis group (mean \pm SD: $39.47 \pm 3.37 \%$ ) ( $p$ $<0.05)$. It was also observed that most of the Ki-67 positive cells were found in the suprabasal layer in all the psoriasis cases while it was located in basal layer in the case of psoriasiform dermatitis. This high Ki-67 positive cells indicates increased in the mitotic index which suggests that there is hyperproliferation of keratinocytes in the suprabasal layer of the psoriatic skin lesions.

\section{Discussion}

Psoriasis is a chronic, papulosquamous disease of the skin characterized by hyperproliferation of the keratinocytes in the epidermis along with inflammation in both epidermis and dermis of the skin $^{11,12}$ which manifests as dull, red sharply delineated scaly plaques. ${ }^{13}$ There is alteration of $\mathrm{T}$ cell function which releases cytokines on genetically predisposed individuals. ${ }^{3}$ Bonifati $\mathrm{C}$ et al ${ }^{14}$, Vestergaard $\mathrm{C}$ et $\mathrm{al}^{15}$ and Takada $\mathrm{Y}$ et $\mathrm{al}^{16}$ described the role of cytokines and growth factors in the epidermal keratinocyte hyperproliferation, increased neovascularisation and inflammation in their studies. Takada Y et $\mathrm{al}^{16}$ also commented that there is activation of NF-kappaB which may have a major role in the keratinocyte survival and abnormal proliferation.

Histopathological diagnosis is considered as the gold standard for the diagnosis of psoriasis. ${ }^{1}$ However, it becomes difficult to differentiate other psoriasiform dermatitis from psoriasis as it can mimic psoriasis histologically and clinically making the diagnosis difficult for the dermatopathologists. ${ }^{17}$ Therefore, features such as elongation of rete ridges and hyperplasia of the epidermis which are the characteristics of psoriasiform dermatitis are seen in psoriasis as well as other psoriasiform dermatitis(e.g. lichen simplex chronicus, pityriasis rosea and pityriasis rubra pilaris). Besides these features, presence of interchanging vertical and horizontal parakeratosis in pityriasis rubra pilaris and mounds of parakeratosis with leakage of red blood cells in pityriasis rosea are specific for their diagnosis. However, these features are not present in every case. ${ }^{2}$ Therefore, it is a diagnostic dilemma for the dermatopathologists to differentiate psoriasis from psoriasiform dermatitis when there is a lack of typical features. The basis of this study is to aid in the diagnosis.

Although the prevalence of psoriasis is $2.2 \%-2.6 \%$ in Western countries $^{18}$, it is found to be lower in Asian population which is around $0.3 \%$ in one study ${ }^{19}$ and $1.2 \%$ in another study ${ }^{20}$ which is comparable to the present study $(0.2 \%)$. Das $\mathrm{S}$ et $\mathrm{al}^{21}$ reported $1.24 \%$ prevalence in North east India which is higher than the current study $(0.2 \%)$.
There was no agreement about whether there is a difference in the prevalence of psoriasis between males and females. ${ }^{22}$ Many studies did not find any differences in the distribution of psoriasis between genders. . $^{23,24}$

In their study, Mendonca SM et $\mathrm{al}^{17}$ reported leg (19.23\%), foot $(17.3 \%)$ and back $(15.38 \%)$ as the most common site of presentation. This is comparable to the present study as foot (29\%), leg $(24 \%)$ and back $(20 \%)$ were the most common sites of psoriasis. Bedi $\mathrm{TR}^{25}$ reported scalp as the most common site of involvement (78\%) followed by lower limb $(75 \%)$ which differ from the present study (5\%). The difference may be due to small sample size in the current study in comparison to the other study.

Pruritis was the most common findings in studies done by Bedi $\mathrm{TR}^{25}(81 \%)$, Kaur I et $\mathrm{al}^{26}(68 \%)$ and Adam B ${ }^{27}(32.5 \%)$. These findings are consistent with the present study (75\%).

$\mathrm{Ki}-67$ is a widely used cell proliferation marker. It is expressed in all the phases of the cell cycle i.e., $\mathbf{G}_{1}, \mathrm{~S}, \mathrm{G}_{2}$ and mitosis except in $G_{0}$ phase ${ }^{5,6}$ and therefore, it is useful in the detection of epidermal hyperproliferation. Amin MM et $\mathrm{al}^{11}$ observed the over expression of $\mathrm{Ki}-67$ in the psoriatic epidermis in comparison to non-lesional skin which proved the relationship of Ki-67 with hyperproliferation in the epidermis. Zhang JM et al $^{28}$ suggested abnormality in the cell cycle of the keratinocytes present in psoriatic epidermis by studying the over-expression of Ki-67 and PCNA in psoriasis. It was noted that Ki-67 is a good indicator of hyperproliferative cells in the epidermis of psoriasis. ${ }^{8}$ Doger FK et $\mathrm{al}^{7}$, Ando $\mathrm{M} \mathrm{et} \mathrm{al}^{29}$ and Kim $\mathrm{SA}$ et $\mathrm{al}^{30}$ proved that Ki-67 expression is higher in psoriatic epidermis when compared to normal epidermis which indicates that it is a good marker for detecting the proliferating keratinocytes in psoriasis in their respective studies. Batinac $\mathrm{T}$ et $\mathrm{al}^{31}$ observed an increased in Ki-67 expression in the involved skin in psoriasis (17.05) as compared to normal skin (3.65). Different studies shows a variable Ki-67 positivity index in psoriatic skin lesions when compared to the present study [Table 2].

Table 2 : Showing comparison of Ki-67 positivity index in psoriasis.

\begin{tabular}{|c|c|c|c|}
\hline Study & $\begin{array}{c}\text { Ki-67 } \\
\text { positivity } \\
\text { index(\%) }\end{array}$ & Year & Method \\
\hline Doger FK et al $^{7}$ & $18.12 \pm 12.39$ & 2007 & $\begin{array}{l}500 \text { keratinocytes at } \\
400 \mathrm{X} \text { magnification }\end{array}$ \\
\hline$\underset{\mathrm{al}^{11}}{\text { Amin MIM et }}$ & 28.6 & 2012 & $\begin{array}{l}\text { Keratinocytes } \\
\text { staining in basal } \\
\text { lower and total } \\
\text { epidermis }\end{array}$ \\
\hline Sezer E et $\mathbf{a}^{12}$ & $86.0 \pm 4.4$ & 2015 & $\begin{array}{c}\text { Suprabasal/total } \\
\text { epidermal } \\
\text { ratio } / \mathrm{mm}^{2}\end{array}$ \\
\hline$\underset{\mathrm{al}^{32}}{\text { Ramezani M et }}$ & $21.6 \pm 10$ & 2019 & $\begin{array}{c}>/=25 \% \text { of } \\
\text { epidermal cells }\end{array}$ \\
\hline $\begin{array}{c}\text { Mendonca SMI } \\
{\text { et } \mathrm{al}^{17}}^{17}\end{array}$ & 2.86 & 2020 & $\begin{array}{c}\text { Suprabasal } \\
\text { mitosis/100 HPF }\end{array}$ \\
\hline Present study & $71.65 \pm 4.99$ & 2020 & $\begin{array}{c}\text { Suprabasal/total } \\
\text { epidermal } \\
\text { ratio } / \mathrm{mm}^{2}\end{array}$ \\
\hline
\end{tabular}

Sezer E et $\mathrm{al}^{2}$ suggested a cut-off value of $75 \%$ for the suprabasal/total epidermal cell count ratio to differentiate psoriasis from other psoriasiform dermatitis. In the present study, the mean suprabasal Ki-67 positivity index (suprabasal/total epidermal cell count ratio) was also found significantly higher in psoriasis (mean \pm SD : $71.65 \pm 4.99 \%$; range: $60.57 \%-81.13 \%$ ) than the psoriasiform dermatitis group (mean \pm SD : $39.47 \pm 3.37 \%$; range: $34 \%-45.16 \%$ ) ( $p<$ 
0.05). These suggests that Ki-67 positive cells were more abundant in suprabasal layer $(>50 \%)$ out of the total epidermal Ki-67 positive cells in all psoriasis whereas it was lower in all the cases of psoriasiform dermatitis $(<50 \%)$. In a similar study, Ramezani $\mathrm{M}$ et $\mathrm{al}^{32}$ considered high expression $(\geq 25 \%)$ of $\mathrm{Ki}-67$ in the epidermal cell nuclei as positive in psoriasis as well as psoriasiform dermatitis groups. They observed higher counts in psoriasiform dermatitis (29 $\pm 11.6 \%$ ) compared to psoriasis group (mean: $21.6 \pm 10 \%$ ). This was in contrast to the present study. This may be due to the different methods of counting of the cells, they did not use suprabasal/total epidermal cell count but they counted total epidermal cells and predicted epidermal cells positive for Ki67 in whole epidermis. A selection criteria $\geq 25 \%$ as cut-off was used in their study which was different from the present study and Sezer E et al. ${ }^{2}$ Moreover, majority of their cases were chronic eczema. The difference in the findings of these various studies may be due to the difference in the methods of counting the Ki-67 positive keratinocytes and due to the difference in the Ki-67 primary antibody kit. Another main reason could be the selection of the sample and the small sample size.

\section{Conclusion}

This study observed that in psoriasis $>50 \%$ of the Ki-67 positive keratinocytes were found in the suprabasal layer of the epidermis while it was $<50 \%$ in the case of psoriasiform dermatitis. It can be concluded that suprabasal Ki-67 mitotic index will be of definitive help to the dermatopathologists in diagnosing psoriasis in addition to the classical histological picture and also in differentiating it from other psoriasiform dermatitis.

\section{References}

1. Elder DE. Lever's Histopathology of skin. 10th ed. Philadelphia:Lippincott Williams andWilkins;2009.174-81.

2. Sezer E, Boer-Auer A, Cetin E, Tokat F, Durmaz E, Sahin S, et al. Diagnostic utility of Ki-67 and Cyclin Dl immunostaining in differentiation of psoriasis vs. other psoriasiform dermatitis. Dermatol Pract Concept J 2015;5(3):7-13.

3. Calonje E, Brenn T, Lazar A, McKee PH. McKee's Pathology of the Skin. 4th ed. London:Elsevier Saunders;2012.206-10.

4. Cuylen S, Blaukopf C, Politi AZ, Muller-Reichert T, Neumann B, Poser I, et al. Ki67 acts as a biological surfactant to disperse mitotic chromosomes. Nature 2016;535(7611):308-12.

5. Bruno S, Darzynkiewicz Z. Cell cycle dependent expression and stability of the nuclear protein detected by Ki-67 antibody in HL-60 cells. Cell Prolif 1992;25(1):31-40.

6. Sawhney N, Hall PA. Ki-67-structure, function and new antibodies. J Pathol 1992;168(2):161-2

7. Doger FK, Dikicioglu E, Ergin F, Unal E, Sendur N, Uslu M. Nature of cell kinetics in psoriatic epidermis.J Cutan Pathol 2007;34(3):257-63.

8. Gudjonsson JE, Johnstone A, Sigmundsdottir H, Valdimarsson H. Immunopathogenic mechanisms in psoriasis. Clin Exp Immunol 2004;135(1):1-8.

9. Vissers WH, Arndtz CH, Muys L, Van Erp PE, de Jong EM, van de Kerkhof PC. Memory effector (CD45RO+) and cytotoxic (CD8+) T cells appear early in the margin zone of spreading psoriatic lesions in contrast to cells expressing natural killer receptors, which appear late. Br JDermatol 2004;150(5):852-9.

10. Jesionek-Kupnicka D, Chomiczewska-Skora D, Rotsztejn H. Influence of phototherapy on Ki-67 antigen expression: A preliminary study. Pol J Pathol 2013;64(2):96-103

11. Amin MM, Azim ZA. Immunohistochemical study of osteopontin, Ki-67, and CD34 of psoriasis in Mansoura, Egypt. Indian J of Pathol and Microbiol 2012;55(1):56-60.

12. Rashmi R, Rak KS, Basavaraj KH. A comprehensive review of biomarkers in psoriasis. Clin Exp Dermatol 2009;34(6):658-63.

13. Schaller G, Meyer-Hermann M. A modeling approach towards epidermal homoeostasis control.JTheor Biol 2007;247(3):554-73.

14. Bonifati C, Ameglio F. Cytokines in psoriasis. Int J Dermatol 1999;38(4):241-51.

15. Vestergaard C, Johansen C, Otkjaer K, Deleuran M, Iversen L. Tumor necrosis factor- $\alpha$-induced CTACK/CCL27 (cutaneous T-cell-attracting chemokine) production in keratinocytes is controlled by nuclear factor $\mathrm{kB}$. Cytokine 2005;29(2):49-55.

16. TakadaY,Singh S, Aggarwal BB. Identification of a p 65 peptide that selectively inhibits NF-kappa B activation induced by various inflammatory stimuli and its role in down-regulation of NF-kappaB-mediated gene expression and upregulation of apoptosis.J Biol Chem 2004;279(15):15096-104.

17. Mendonca SM, Devaraju S. Suprabasal mitotic index: A cell kinetic aid in psoriasis diagnosis. Indian J Dermatopathol Diagn Dermatol 2017;4(1):2-7.

18. Gelfand JM, Stern RS, Nijsten T, Feldman SR, Thomas J, Kist J, et al. The prevalence of psoriasis in African Americans: results from a populationbased study.J Am Acad Dermatol 2005;52(1):23-6.

19. Yip SY. The prevalence of psoriasis in the Mongoloid race. J Am Acad Dermatol 1984;10(6):965-8.

20. Lin XR. Psoriasis in China.JDermatol 1993;20(12):746-55.

21. Das S, Adhicari P. A hospital-based clinical study of childhood psoriasis in a tertiary care center of Northeast India. Indian J Pediatr Dermatol 2018;19(4): 321-5.

22. Parisi R, Symmons DP, Griffiths CE, Ashcroft DM; Identification and Management of Psoriasis and Associated Comorbidity (IMPACT) project team. Global epidemiology of psoriasis: a systematic review of incidence and prevalence.J Invest Dermatol 2013;133(2):377-85.

23. Tsai TF, Wang TS, Hung ST, Tsai PI, Schenkel B, Zhang M, et al. Epidemiology and comorbidities of psoriasis patients in a national database in Taiwan. J Dermatol Sci 2011;63(1):40-6.

24. Yang YC, Cheng YW, Lai CS. Prevalence of childhood acne, ephelides, warts, atopic dermatitis, psoriasis, alopecia areata and keloid in Kaohsiung County, Taiwan: a community-based clinical survey. J Eur Acad Dermatol Venereol. 2007;21(5):643-9.

25. Bedi TR. Psoriasis in north India. Geographical variations. Dermatologica 1977;155(5):310-4.

26. Kaur I, Handa S, Kumar B. Natural history psoriasis: a study from the Indian subcontinent.J Dermatol 1997;24(4):230-4.

27. Adam B.Psoriasis in hospital population. Med J Malaysia 1980;34:370-74

28. Zhang JM, Huang GS, Zhou CH. Expression of P57 (kip2), PCNA and Ki67 in psoriatic lesion.J Chin Trop Med 2009;9(3):453-4.

29. Ando M, Kawashima T, Kobayashi H, Ohkawara A. Immunohistological detection of proliferating cells in normal and psoriatic epidermis using Ki-67 monoclonal antibody.J Dermatol 1990; 1(6):441-6.

30. Kim SA, Ryu YW, Kwon JI, Choe MS, Jung JW, Cho JW. Differential expression of cyclin D1, Ki-67, pRb, and P53 in psoriatic skin lesions and normal skin. Mol MedRep 2018;17(1):735-42.

31. Batinac T, Zamolo G, Hadzisejdi $\square$ I, Zauhar G, Brumini G, Ruzi $\square$ A, et al. Expression of Bcl-2 family proteins in psoriasis. Croat Med J. 2007;48(3):31926.

32. Ramezani M, Shamshiri A, Zavattaro E, Khazaei S, Rezaei M, Mahmoodi R, et al. Immunohistochemical expression of P53, Ki-67, and CD34 in psoriasis and psoriasiform dermatitis. Biomedicine (Taipei) 2019;9(4):36-41. 